Volume 3

Number 4 Critical Perspectives on Marketing

from Japan - Part 2

Article 5

2018

\title{
Yukari Mitsuhashi, Ikigai: Giving every day meaning and joy (2018)
}

Yasuko Takayama

Shizuoka University of Art and Culture

Follow this and additional works at: https://digitalcommons.uri.edu/mgdr

Part of the Family, Life Course, and Society Commons, and the Psychology Commons

\section{Recommended Citation}

Takayama, Yasuko (2018) "Yukari Mitsuhashi, Ikigai: Giving every day meaning and joy (2018)," Markets, Globalization \& Development Review. Vol. 3: No. 4, Article 5.

DOI: 10.23860/MGDR-2018-03-04-05

Available at: https://digitalcommons.uri.edu/mgdr/vol3/iss4/5

This Book Review is brought to you for free and open access by DigitalCommons@URI. It has been accepted for inclusion in Markets, Globalization \& Development Review by an authorized editor of DigitalCommons@URI. For more information, please contact digitalcommons-group@uri.edu. 
Yukari Mitsuhashi, Ikigai: Giving every day meaning and joy (2018)

\section{Markets, Globalization \& Development Review}
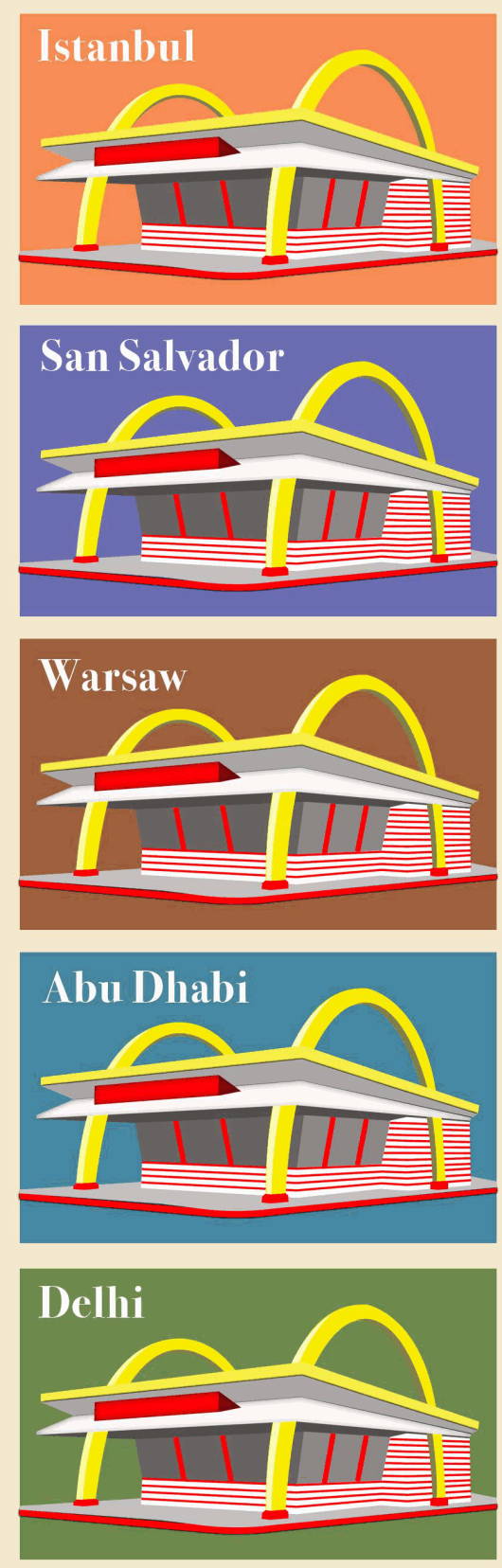
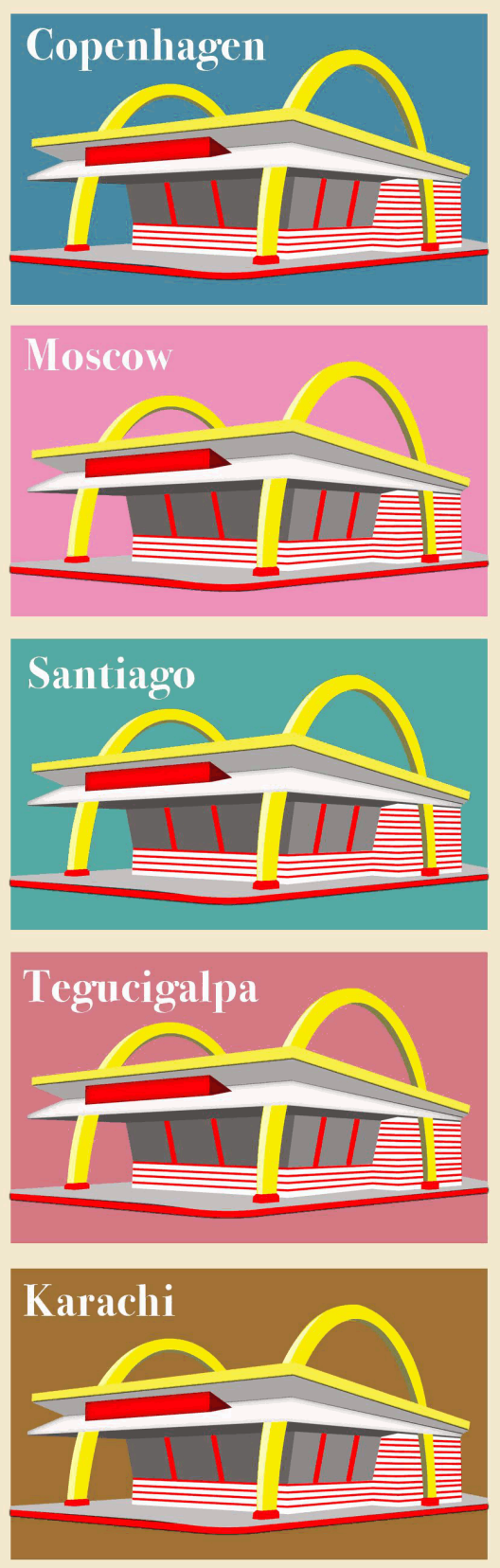
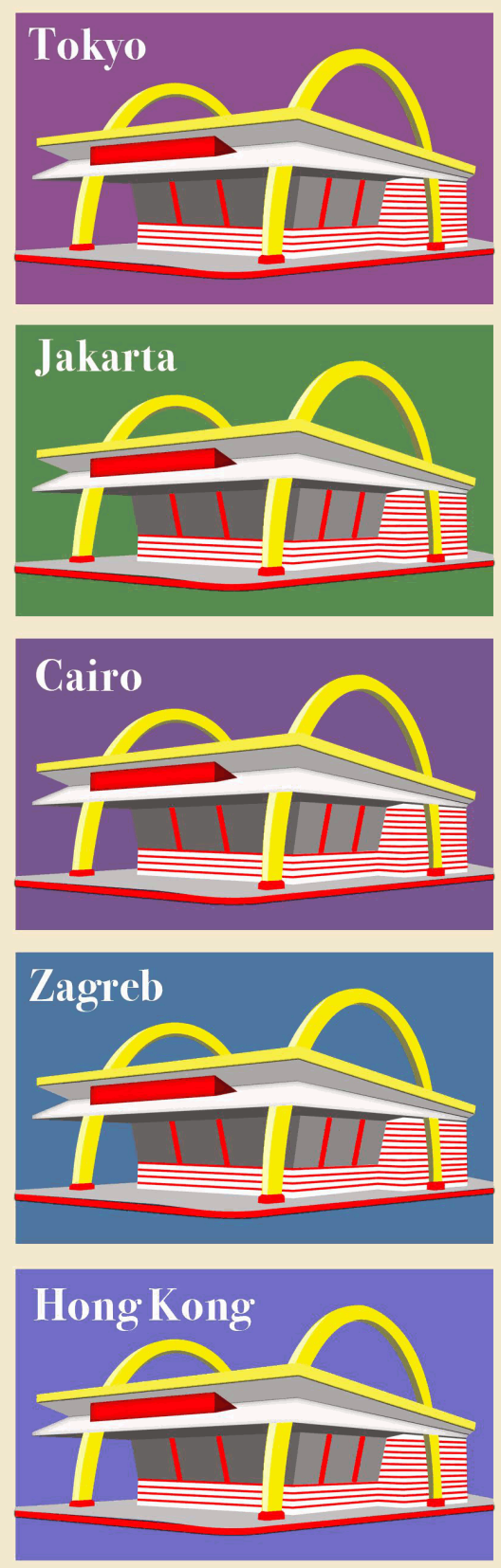

This book review is available in Markets, Globalization \& Development Review: https://digitalcommons.uri.edu/mgdr/ 


\section{Book Review}

\section{Yukari Mitsuhashi, Ikigai: Giving Every Day Meaning and Joy (2018)}

Almost all Japanese people possess an abstract concept of 'ikigai' without thinking about it deeply in their daily lives - because having it is thought to be an essential part of living happily. Although most Japanese can answer whether they have ikigai or why so, it is, however difficult to arrive at an exact definition of ikigai because it means something different to each person, and it even changes throughout the course of one's lifetime.

There have been many books and research studies on ikigai in Japan and, recently, it has begun receiving attention around the world. For many, however, it is still a vague concept. Yukari Mitsuhashi, the author of Ikigai: Giving every day meaning and joy, tries to help readers develop an instinctive understanding of ikigai through a reflection on binary opposite terms, and via interviews with highly respected people. Based on her personal understanding of ikigai, Mitsuhashi (2018a) positions readers to ask themselves various questions that encourage them to think deeply about ikigai and discover their own sense of it. Readers may want to look at or revisit the MGDR paper by Suzuki (2018) that also explores the complex aspects of personal meaning creation by media in Japanese contexts.

Yukari Mitsuhashi is a freelance journalist and writer based in Los Angeles. She writes extensively on topics about marketing as well as articles in women's magazines. She has written about Japanese IT in the English-language daily Japan Times and on cutting-edge IT news from outside of Japan on her blog, TechDoll.jp. Mitsuhashi grew up in Tokyo and spent most of her childhood in Japan before moving to New York with her family. After graduating from Keio University in 2004, she began working as a freelance translator and writer. After working as a freelancer, she began using Twitter, which was not yet common in Japan at the time. Responding to requests from her Twitter followers, she set up a personal blog, which attracted the attention of online media and publishers, who started carrying her writing. Of her books, Ikigai: Giving every day meaning and joy is the latest.

\section{Overview of the Chapters}

Let me begin by an overview of the book. In chapter 1, Mitsuhashi (2018a) first reviews all the web information, research studies, and books that refer to ikigai and - following this - she makes several references to them, adding her own descriptions and trying to settle on a clear definition. She also gives readers a background on why such a sense of value exists in Japan, based on some aspects of Japanese 
culture, such as the short Japanese poem form of Haiku and words and phrases that express the concept of "moments of daily life".

Mitsuhashi states that "ikigai can be interpreted as the values in your life that make it worth living. However, each person's ikigai is unique because we all find joy in different aspects of life. There is no right or wrong answer" (pp.14-15). Other authors who have written about ikigai describe ikigai in similar ways in their books. Mitsuhashi also quotes the Japanese author and psychiatrist Mieko Kamiya who compares "ikigai to a kind of happiness, but, perhaps the main difference between shiawase (the Japanese word for happiness) and ikigai is that ikigai carries with it the idea of moving toward the future" (Kamiya 1966).

In Chapter 2, Mitsuhashi prompts readers to grasp their own image of ikigai by having them compare sets of opposite binary terms in $A>B$ format. Mitsuhashi chose the word sets based on several interviews about ikigai with notable people. The opposite terms are listed below:

Everyday life > Lifetime

External world > Internal world

Giving > Receiving

Fluid > Fixed

Emotional > Logical

Specific > Abstract

Active $>$ Passive.

For example, concerning "Emotional > Logical" binary terms, she explains that "An essential element of ikigai is that it is based on emotions rather than logic. Ikigai is something you feel with your heart rather than something you think with your head" (pp.27-28).

At the end of the chapter, she discusses what ikigai offers, stating that it "brings you focus and direction, and serves as an anchor in your life."

In Chapter 3 titled "Interests and Ikigai," Mitsuhashi offers some tips for finding ikigai. Readers who were able to capture an image of ikigai from the previous chapter can gain an even more concrete understanding of it from the keyword descriptions in Chapter 3 about hobbies, food culture and volunteer work, all of which can provide good opportunities for finding your own ikigai.

In Chapter 4, Mitsuhashi talks about the relationship between ikigai and work. She speaks to readers about the importance of finding ikigai in their careers, and how it can make working - even in less than ideal conditions - feel worthy and satisfying. One of the ways she suggests to make work feel more worthwhile is through "job crafting", a process developed by Dr. Jane Dutton, in which one answers a series 
of questions designed to help find ikigai at work. The first set of questions in Chapter 4 helps the reader become more aware of how they are doing at work, which is the first task of successful job crafting. The questions are below.

- What tasks am I doing?

- How do I feel about these tasks?

- How am I spending my time?

- Who am I talking to or connecting to virtually or in reality?

In Chapter 5, Mitsuhashi includes transcripts of interviews with people who have had distinguished careers. Readers are expected to draw their own conclusions about the meaning of ikigai from these interviews. It seems, however, that the most important point that Mitsuhashi is trying to emphasize in this chapter is that one's sense of ikigai may change depending on the life-stage that they are in. In her interviews, six people answer the following questions:

- What is your ikigai?

- What does ikigai provide for you and your life?

- Has your ikigai changed over time?

- Has ikigai helped you in times of difficulty?

- How did you discover your ikigai?

- How does ikigai fit into your daily life?

In Chapter 6, the final chapter of the book, Mitsuhashi summarizes her answer about the concept of ikigai, the benefit of having it and approaches to finding it. She says that knowing your ikigai - or at least the values that lie beneath it - will help one discover other ways to be fulfilled in one's next life stage (p. 97). In other words, Ikigai does not have to be sought after in only one defined situation or environment. Because ikigai is about knowing oneself, when searching for it, one needs to look at both one's current life as well as one's past. In order to do that, in this final chapter, Mitsuhashi presents questions in a timeline from past to future. Mitsuhashi concludes the chapter by stating, "Happiness is the result of having or feeling ikigai. You can't find ikigai by sitting around the house, because ikigai is the action we take in the pursuit of happiness" (p.103).

\section{Delving Deeper into the Book}

As mentioned earlier, there is much literature on ikigai in Japan: about what it is, why it gives people the power to live, how it can be obtained, and why the word ikigai exists only in Japanese. Most people who are 
interested in the topic are also likely to be interested in the relationship between ikigai and Japanese culture. Mitsuhashi only refers briefly, however, to elements of Japanese culture such as Haiku expressions, and Japanese words that describe "attention in the present moment". Mitsuhashi also refers to Japanese food culture in Chapter 3, referring to it as an element of ikigai in daily life. Some readers might feel that the sudden introduction of food culture here is a little strange. Other authors, such as Mogi (2017) and García and Miralles (2017) - who published books on ikigai around the same time as Mitsuhashi (2018a) published hers - also talk about Japanese food culture in detail, and both refer to the detailed attention that famous sushi chef Sukiyabashi Jiro pays to the simple repetitive processes of making perfect sushi as an example of how ikigai can lead to great achievements (those who are interested in learning more about this topic can watch the documentary entitled 'Jiro Loves Sushi'; Gelb, 2011 - see also Figure 1). Although one can achieve fantastic results from having ikigai, Mitsuhashi (2018a), Mogi (2017), and García and Miralles (2017) all state that results are only a byproduct. In order to truly understand ikigai, one must focus on the process and not on the outcome.

\section{Figure 1: Sushi Aesthetics}

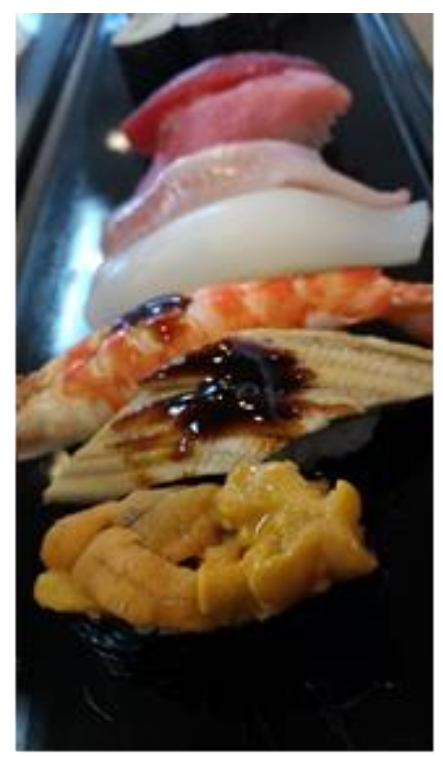

Source: Yasuko Takayama

For those readers who are particularly interested in ikigai in the context of its Japanese cultural background, Mogi's book about ikigai may be more gratifying. Although his observations are not based on purely academic evidence, it may help to understand the pure essence of ikigai because he describes it through an explanation of the unique 
values and feelings of Japanese people who are engaged in traditional aspects of Japanese culture. Mitsuhashi often maintains that the purpose of her book is to help readers gain a better grasp of the Japanese notion of ikigai and, more importantly, to inspire them to think about finding their own sense of it. In this regard, Chapter 2 offers the most unique and valuable insight. It prompts readers toward a deeper understanding by having them compare the binary opposite terms that express some of the elements of ikigai. Other writers have tried to describe ikigai to people outside of Japan by presenting various examples of it. Indeed, the more detail there is in the descriptions of ikigai, the greater the chance one will have to reflect on one's own values, even though ikigai holds different meanings for different people. On the other hand, however, describing ikigai in a few words runs the risk of being hard to understand. That is why the exercises that Mitsuhashi offers in Chapter 2 are effective in getting readers to understand ikigai instinctively, provided that they keep in mind the fact that even the exercises Mitsuhashi presents are to some degree a reflection of her own values. Mitsuhashi also discusses the benefits that can be derived from knowing what 'you' want and what 'you' value in life. In this case, "you" does not refer to all people, but only to a certain generation of targeted readers who are searching for "growth and progress," whom Mitsuhashi hopes to reach. When talking about her book in a website interview by Mynavi BOOKS, Mitsuhashi (2018b) indicated that her publisher asked her to write a book aimed at young people in their twenties and thirties who are starting their careers. That is why many of her examples refer to making career choices, which she considers to be one of the book's main topics.

The core part of this book is Chapter 4, where Mitsuhashi (2018a) talks in detail about how to find ikigai in one's job, or even how to turn one's job into ikigai. It is clear that Mitsuhashi currently derives her sense of ikigai from her career. As she cautions her readers, however, this may change in the future depending on her life circumstances.

At the end of this chapter, Mitsuhashi presents four questions to ask oneself in order to accomplish the "job crafting" proposed by Professor Dutton. As Mitsuhashi mentions, it is very hard to completely separate work from life, and some people - out of necessity - need to devote themselves 100 percent to their work. In those cases, she says it is especially worthwhile to find ikigai at work. Mitsuhashi (2018a) and García and Miralles (2017) both refer to Figure 2 ("What's your ikigai?"), originally created by Marc Winn, wherein the lower part of the bottom circle it is written "that which you can be paid for". Although this diagram seems to be recognized around the world, Japanese people who are familiar with ikigai may find it a little strange because Ikigai is not usually associated with financial compensation, as Mitsuhashi mentions early in her book. The general point that the diagram seems to be depicting, 
however, is why so many people find ikigai in their work. Some people become so connected to work that losing their jobs causes them to be unable to find any reason to live, even resorting to suicide. The high rate of suicide in Japan is well known around the world. One of the reasons for this is that Japanese people devote so much of themselves to their sense of duty. Although this can have terrible consequences, many Japanese feel that having a strong sense of duty is an important part of life because that is how they are able contribute to and connect with society. The reason Mitsuhashi describes so many methods for finding ikigai in one's career, therefore, might be a reflection of her desire to help those who have lost their ikigai and want to find it again. Moreover, it is clear that Mitsuhashi herself has found her ikigai in what she does for a living, as it is substantiated by her selection of interviews in Chapter 5.

Figure 2: What's your ikigai?

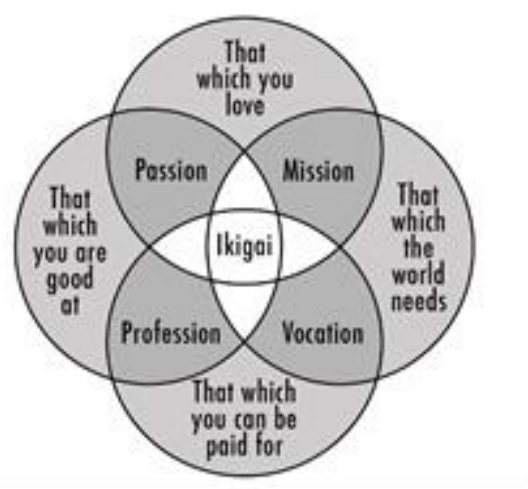

Source: Winn, Mark (2014), "What's your ikigai?”, The View Inside Me, (accessed Octover 1, 2018), [available at http://theviewinside.me/whatis-your-ikigai/]

In Chapter 6, Mitsuhashi targets her main message at the younger generation of readers in their twenties and thirties who are spending the very time that has just passed for her. Some of what she herself felt as a successful freelancer writer can be experienced by the readers if they are "healthy people in their twenties and thirties who are capable of working". Through her message, she tries to encourage them and provoke them to act, acting as a kind of self-development guide. In this regard, Chapter 6 works just as Mitsuhashi intended. However, the Japanese idiom 'Junin Toiro (ten people, ten colors)' suggests that - as people have uniquely individual characters - each person's sense of ikigai is uniquely different because we can all find joy in different aspects of life. That is why it would not be surprising if some readers from the same or a different generation had a different impression of ikigai.

In his book, "-ikigai wo motomete- ningen no jijitsu 1 (Striving for Ikigai The Truth of Human Beings)", Yanagida (1997) states that most 
often the ikigai we form when we are healthy is based on the premise that we can continue to actively participate in society forever. Kamiya (1966) as well as Yanagida (1997), however, discuss in their respective books several cases of people who have found ikigai even though they are in bad health or living in very difficult conditions. Mistuhashi does not cover this point in her book, therefore it may be hard for some readers to fully understand ikigai, especially those who may be suffering from ill health or are unable to participate actively in society. Based on the references at the end of her book, however, this reviewer believes that Mitsuhashi has a strong understanding of ikigai, even though it is clear that her book is aimed at a specific demographic segment of readers within a limited number of pages.

For those who are interested in ikigai but do not fall within Mitsuhashi's targeted audience, the author recommends reading other books on ikigai as well.

\section{Concluding Comments}

After conducting a keyword search of 'ikigai', there were 3,264 articles published within the last 10 years on CiNii (Scholarly and Academic Information Navigator). At a glance, the keyword that appeared most commonly was "elderly" and the second most common keyword was "disease". Many contained both keywords together. Why do so many researchers study about the effect that ikigai has on people in unfortunate circumstances? Because most of the research concludes that those who have found ikigai seem to be able to stay calm and be happy under any circumstances and that it is connected to their longevity and an improvement in their quality of life.

In Buddhism, there is a phrase "Satori wo Hiraku", which means attaining spiritual enlightenment, or achieving a state where one can perceive everything clearly without worry or suffering. Many Buddhists train themselves to achieve this level of consciousness. Finding ikigai may be similar to Satori, but more inwardly focused. According to the teachings of Jodo Shinshu (The True Essence of Pure Land Buddhist Teaching), people can achieve 'Enlightment' after death and all their "suffering" disappears, but in order to have a chance at doing so, one needs to make every effort to live meaningfully during their lifetime. This being said, however, to find ikigai, one need not writhe in agony like ascetic trainee monks do because ikigai is supposed to keep us calm and happy. It does not need to be something special. The common values that lie beneath one's ikigai from past life stages can also be used to find ikigai in the future. Even if one is unable to fully awaken one's ikigai during a lifetime, it does not matter because one can find happiness as a result of accumulating it. Although this may sound ephemeral to some, finding ikigai is believed to be one of the most important elements to living a happier life for Japanese centenarians 
who have managed to live in a rapidly changing and stressful modern day society. 


\section{References}

CiNii (Scholarly and Academic Information Navigator, pronounced "sighknee") is a database service which can be searched with academic information of articles, Books, Journals \& Dissertations.

Gelb, David (2011), Director, "JIRO DREAMS OF SUSHI, U.S.A.", Magnolia Pictures, (accessed Octover 1, 2018), [available at Official Movie Site: http://www.magpictures.com/jirodreamsofsushi/]

Héctor, García and Francesca Miralles (2017), Ikigai: The Japanese Secret to a Long and Happy Life. X-Knowledge Co. Ltd., Tokyo, Japan

Kamiya, Mieko (1966), ikigai ni tsuite(About Ikigai). Misuzu Shobo, Tokyo, JAPAN.

Mogi, Ken (2017), The Little Book of Ikigai: The secret Japanese way to live a happy and long life. Quercus Publishing, London, UK

Mitsuhashi, Yukari (2018a), Ikigai: Giving every day meaning and joy. Kyle Books: UK.

Mitsuhashi, Yukari (2018b), Interview with Mynavi BOOKS, Mynavi Publishing, (accessed Octover 1, 2018), [available at https://book.mynavi.jp/macfan/detail summary/id=88388]

Suzuki, Satoko (2018), "Revisiting the Creation of Meaning by Media: A Perspective from Japan," Markets, Globalization \& Development

Review, 3 (1), Special Issue, Article 3. https://doi.org/10.23860/MGDR2018-03-01-04

Winn, Mark (2014), "What's your ikigai?", The View Inside Me, (accessed Octover 1, 2018), [available at http://theviewinside.me/what-isyour-ikigai/]

Yanagida, Kunio (1997), "Ningen no Jijitsu 1 lkigai wo Motomete (Truth of human being 1. Wishing for ikigai )", Japan, Bungeishunju Ltd, Tokyo, Japan. 